\title{
Dose-effect study of Gelsemium sempervirens in high dilutions on anxiety-related responses in mice
}

\author{
Paolo Magnani • Anita Conforti • Elisabetta Zanolin • \\ Marta Marzotto • Paolo Bellavite
}

Received: 10 February 2010 / Accepted: 26 March 2010/Published online: 20 April 2010

(C) The Author(s) 2010. This article is published with open access at Springerlink.com

\begin{abstract}
Introduction This study was designed to investigate the putative anxiolytic-like activity of ultra-low doses of Gelsemium sempervirens ( $G$. sempervirens), produced according to the homeopathic pharmacopeia.

Methods Five different centesimal (C) dilutions of $G$. sempervirens (4C, 5C, 7C, 9C and 30C), the drug buspirone $(5 \mathrm{mg} / \mathrm{kg})$ and solvent vehicle were delivered intraperitoneally to groups of ICR-CD1 mice over a period of 9 days. The behavioral effects were assessed in the open-field (OF) and light-dark (LD) tests in blind and randomized fashion. Results Most G. sempervirens dilutions did not affect the total distance traveled in the $\mathrm{OF}$ (only the $5 \mathrm{C}$ had an almost significant stimulatory effect on this parameter), indicating that the medicine caused no sedation effects or unspecific changes in locomotor activity. In the same test, buspirone induced a slight but statistically significant decrease in locomotion. G. sempervirens showed little stimulatory activity on the time spent and distance traveled in the central zone of the OF, but this effect was not statistically significant. In the LD test, G. sempervirens increased the \% time spent in the light compartment, an indicator of anxiolytic-like activity, with a statistically significant effect using the $5 \mathrm{C}, 9 \mathrm{C}$ and $30 \mathrm{C}$ dilutions. These effects were comparable to those of buspirone. The number of transitions between the compartments of the LD test markedly
\end{abstract}

P. Magnani $\cdot$ M. Marzotto $\cdot$ P. Bellavite $(\triangle)$

Dipartimento di Patologia, Università di Verona,

Strada Le Grazie,

37134 Verona, Italy

e-mail: paolo.bellavite@univr.it

A. Conforti $\cdot$ E. Zanolin

Department of Medicine and Public Health, University of Verona,

Verona, Italy increased with G. sempervirens 5C, 9C and 30C dilutions. Conclusion The overall pattern of results provides evidence that $G$. sempervirens acts on the emotional reactivity of mice, and that its anxiolytic-like effects are apparent, with a non-linear relationship, even at high dilutions.

Keywords Gelsemium sempervirens · Animal models of anxiety · Open-field test · Light-dark test · Ultra-low doses . Complementary medicine $\cdot$ Gelsemine $\cdot$ Nanopharmacology

\section{Introduction}

Anxiety and behavioral disorders have a relatively high prevalence in modern society and consume significant financial resources. The most well-known tranquilisers or anxiolytics are those of the benzodiazepine family, which act by modulating the GABAergic receptors, but many others are known, including buspirone and other drugs belonging to the class of azaspirodecanedione compounds, which act as agonists of the serotoninergic receptors (5-HT1A). However, the clinical use of those drugs is not without its drawbacks, particularly due to the risk of side effects such as psychomotor impairment or potentiation of other central depressant drugs (Lader 2008; Cloos and Ferreira 2009). What is more, $25 \%$ of patients with anxiety disorders do not respond sufficiently to first-line treatment (Schosser and Kasper 2009). Benzodiazepines are not recommended for long-term treatment of generalized anxiety disorders, due to associated development of tolerance, cognitive and memory changes, physical dependence and withdrawal reaction on discontinuation (Allgulander et al. 2003). Natural remedies possessing the same efficacy as conventional drugs, but with fewer side effects, would thus be a valuable addition to the treatment options for anxiety-related disorders. 
However, the acceptance of alternative remedies has thus far been hampered by the scarcity of pharmacological studies elucidating their indications, limitations and mechanisms of action (Mamtani and Cimino 2002; Pilkington et al. 2006a, b).

In traditional Materia Medica, Gelsemium sempervirens (G. sempervirens) is described as a remedy for a variety of anxiety-like psychological and behavioral symptoms (Boericke 1927; Barbancey 1987; Guermonprez 2006); however, consistent evidence of its efficacy is lacking. The plant, belonging to the Loganiaceae family, is a twining vine native to warm temperate and tropical America, from Guatemala to the southeastern United States. All parts of this plant contain the toxic strychninerelated alkaloids gelsemine, gelseminine and sempervirine (Schun and Cordell 1987). Gelsemine has been identified as the main urinary marker of Gelsemium exposure (Lai and Chan 2009). Neurological signs characterized by marked progressive weakness and convulsions culminating in death have been observed in goats after ingestion of G. sempervirens and ensuing toxicosis (Thompson et al. 2002); the nectar is also toxic to honeybees (Irwin and Adler 2006). In phytotherapy literature, G. sempervirens has been reported to show sedative, analgesic and anti-seizure properties, though the effective doses are unclear (Valnet 1992; Demarque et al. 1995; Peredery and Persinger 2004). However, it should be noted that this last-mentioned protective effect against convulsions was obtained using an extract mixed with Scutellaria lateriflora and Datura stramonium.

G. sempervirens in high dilutions, prepared according to the homeopathic pharmacopeia, has been investigated by some authors, but the reported results are not always consistent, chiefly due to uncertainty connected with the methodology and a lack of statistical evaluations (Binsard 1979; Binsard et al. 1980; Sukul et al. 1986; Guillemain et al. 1989). There have been two studies in which high dilutions of $G$. sempervirens were found to have a preventive action against experimental stress (electric shock) in mice (Bousta et al. 2001) and against convulsions provoked by lithium and pilocarpine in rats (Peredery and Persinger 2004). In recent trials in our laboratory, $G$. sempervirens showed promising anxiolytic-like effects in the open-field test and appeared to work even at high dilutions (Bellavite et al. 2009a), but a systematic doseresponse study was not performed. There is accordingly scope for further studies exploring the effects of $G$. sempervirens in mouse models of emotional response, and, in particular, for investigating the dose (or dilution)dependence of such effects.

Experimental investigations carried out on highly diluted solutions have suffered from problems of replicability between different laboratories (Bellavite et al. 2006a, b; Witt et al. 2007). It is therefore important for any preliminary results in this field to be confirmed and consolidated through further investigations by independent laboratories, using rigorous protocols and statistical evaluations. We accordingly adopted a carefully defined protocol and applied it to a series of experiments designed to test (a) the null hypothesis that the effect of any drug dilution is similar to that of the control vehicle and (b) whether any dose dependence of the putative effects can be demonstrated. We employed two well-validated models which explore the behavior of mice in novel environments, namely the open-field test (OF) and the light-dark choice test (LD), to acquire various behavioral parameters used in neuropsychopharmacology for drug screening. The OF test (Walsh and Cummins 1976; Simon et al. 1994; Prut and Belzung 2003; Lamprea et al. 2008) is widely used as a test of locomotion since the mice are free to move in the entire field, and the distance traveled during a fixed time can be measured (Mi et al. 2005; de Araujo et al. 2009; Vasconcelos et al. 2009). However, a detailed ethological analysis of the OF test, including time spent and distance traveled in the center/periphery of the field, makes it possible not only to examine general activity but also to detect specific effects of drugs on behavioral parameters such as field exploration propensity and thigmotaxis (Choleris et al. 2001; Ramos et al. 2008; Fukushiro et al. 2009). The two-compartment LD model system (Crawley and Goodwin 1980; Hascoet et al. 2001; Belzung and Griebel 2001; Bourin et al. 2007) is one of the most commonly used behavioral paradigms: classic anxiolytics (benzodiazepines) as well as the newer anxiolytic-like compounds (e.g. serotonergic drugs or drugs acting on neuropeptide receptors) (Bourin and Hascoet 2003) and natural compounds (Chen et al. 2004; de Araujo et al. 2009) can be detected using this paradigm, since they specifically increase the time spent in the lit compartment and the number of exploratory transitions.

Our experiments were performed on unconditioned responses, using ethologicallybased paradigms involving spontaneous reactions to non-painful stimuli. Ethological models were chosen both for ethical reasons and because our aim was to mimic the natural conditions in which behavior is influenced by emotional states of fear, curiosity and anxiety. Ethological observations show that, though rodents naturally tend to explore a novel environment, open fields and illuminated spaces are aversive to them and hence counteract the normal behavioral responses (Griebel et al. 1993; Clement et al. 2007). It is conceivable that these two conflicting drives make the test highly sensitive to even extremely weak stimuli, such as one might expect from ultra-low doses of an active substance. However, ethological models are subject to inter-individual differences and variable behavioral baseline levels (Bourin et al. 2007) so that great care must be 
taken with variable parameters such as environment, handling and testing.

In this work, we sought to investigate the widest possible range of $G$. sempervirens dilutions compatible with the technical constraints and the expected inter-subject variability. Accordingly, we tested the effects of low (4C and 5C), medium (7C and 9C) and high dilutions (30C) of the plant extract. Dilutions such as the 4th and 5 th centesimal (4C-5C) dilutions from crude extracts are expected to contain ultra-low concentrations of the purported active ingredient, but still falling within the molecular range since the dilution factor from the first ethanolic extract (mother tincture) is $10^{8}-10^{10}$ times. On the other hand, dilutions of $12 \mathrm{C}\left(10^{24}\right.$ times $)$ or higher theoretically contain no molecules of the mother tincture since the dilution factor exceeds the Avogadro-Loschmidt limit (Sainte-Laudy and Belon 2009).

Since we used extremely low doses of drugs, the animals were treated using a chronic regimen of one i.p. injection everyday for 8-9 days. As a positive control, we used the 5-HT(1A) agonist buspirone, which is suitable for chronic treatments, in a dose of $5 \mathrm{mg} / \mathrm{kg}$, which is within the dosage range usually employed to detect anxiolyticlike activity in rodents (Cole and Rodgers 1994; Merali et al. 2003; Grundmann et al. 2007; Yamauchi et al. 2008). Partial 5-HT1A agonists like buspirone produce anxiolytic effects in rodents as assessed by the LD test, whereas contrasting results have been reported with full 5-HT1A receptor agonists like 8-hydroxy-2-(di-n-propylamino)tetralin (8-OH-DPAT) (Young and Johnson 1991a; Shimada et al. 1995; Bilkei-Gorzo et al. 1998). The drug-treated animal groups were compared with control groups treated with solutions of the same vehicle used for preparing the drug dilutions.

\section{Materials and methods}

Subjects and handling

Male mice 4-5 weeks old of the ICR-CD1 strain were purchased from Charles River Laboratories (Lecco, Italy) and allowed to acclimate for 2 weeks before testing in a controlled (temperature $22 \pm 2{ }^{\circ} \mathrm{C}$, humidity $55 \% \pm 5 \%$ ) animal facility. At the beginning of the treatments, the bodyweight of animals was $30 \pm 3$ g. For each experiment, 64 mice were randomly distributed, two per cage, in plastic cages (size: $25 \times 14 \times 12 \mathrm{~cm}$ ) and housed with food and water available ad libitum, except during the brief testing periods. Lights were on between 7 a.m. and 7 p.m. The cages were placed in a housing rack consisting of four rows of eight cages each arranged in such a way that cages assigned to different experimental groups were uniformly distributed along rows and columns. The sequence of the groups - and hence the order of injection and testing-was evenly alternated to guarantee similar intervals between operations for the different groups over the course of the experiment. Each animal was used only once in the same test to avoid the confounding effects of learning and habituation. All the experiments were conducted in accordance with the Italian NIH policies on the use of animals in research, and the testing procedures were independently approved by the Animal Ethical Committee of the Interdepartmental Centre for Animal Research (CIRSAL) of Verona University and by the Italian Health Ministry.

\section{Drugs}

The drugs for this study were produced by Boiron Laboratoires, Lyon (F), starting from a whole hydroalcoholic extract of $G$. sempervirens, which was diluted 100 times in $30 \%$ ethanol/distilled water to obtain the $1 \mathrm{C}$ dilution. Subsequent serial $100 \times$ dilutions up to $29 \mathrm{C}$ were then made in the same solvent using glass bottles. After each dilution, the bottle was vigorously agitated using a mechanical shaker. The $3 \mathrm{C}, 4 \mathrm{C}, 6 \mathrm{C}, 8 \mathrm{C}$ and $29 \mathrm{C}$ dilutions were stored in the dark at room temperature. The content of gelsemine-the principal alkaloid of G. sempervirens (Fig. 1) - in the first hydroalcoholic extract was $0.021 \%$ $(\mathrm{w} / \mathrm{v})$, corresponding to a concentration of $6.5 \times 10^{-4} \mathrm{~mol} / \mathrm{l}$. The control solution (vehicle) was the same batch of $30 \%$ ethanol/distilled water solution used to prepare the drug dilutions.

Before being used in each experiment, 0.4-ml samples of the solutions were added to $39.6 \mathrm{ml}$ of distilled sterile and apyrogenic water in a sterile 50-ml Falcon plastic tube, closed with a plastic cap and manually shaken with 20 strong vertical strokes to obtain the final $4 \mathrm{C}, 5 \mathrm{C}, 7 \mathrm{C}, 9 \mathrm{C}$ and $30 \mathrm{C}$ dilutions and control vehicle used for treatments, with final ethanol concentration lowered to $0.3 \%(\mathrm{v} / \mathrm{v})$. Buspirone (Sigma, final dose of $5 \mathrm{mg} / \mathrm{kg}$ ) was diluted in the final vehicle solution $(0.3 \%$ ethanol in distilled water). In

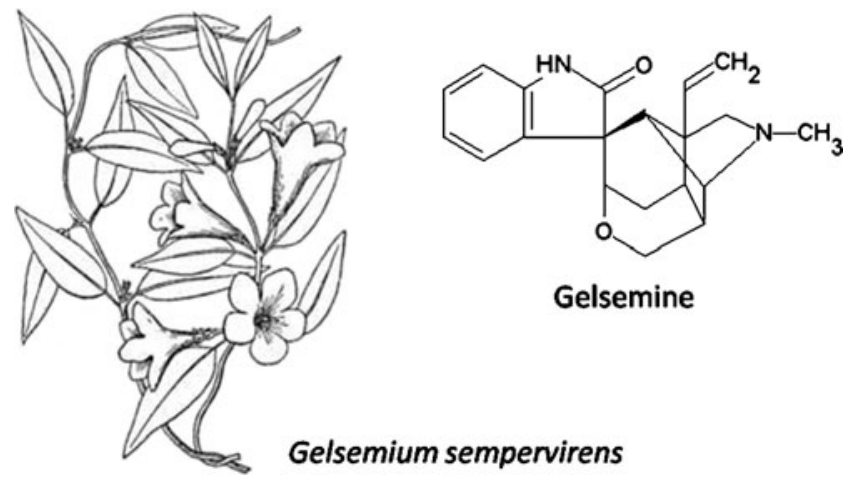

Fig. 1 A drawing of the G. sempervirens plant and the structure of its major alkaloid gelsemine 
order to blind the operators with respect to the test solutions, all the samples were then coded by an independent person and the codes kept sealed inside an envelope until all the tests and calculations were completed. The solutions were distributed in $15-\mathrm{ml}$ sterile Falcon plastic tubes (4 ml/tube), wrapped in aluminum foil and stored at $+4^{\circ} \mathrm{C}$ until the day of use. Before using, each tube was again manually shaken with 20 strokes. All procedures were performed in sterile conditions and using sterile disposable plasticware. The final solutions used for the treatments were tested by gas chromatography and mass spectroscopy for possible contamination with buspirone; the results of these tests were negative.

\section{Treatments}

A minimum required sample size of $n=42$ subjects per group was computed on the basis of previous experience (Bellavite et al. 2009b) and assuming a pre-established statistical power level of 0.9 and an alpha level of 0.05 . Since several doses had to be tested in parallel, the study was conducted with six replications, each with a minimum sample size of eight. Thus, in each experiment, mice were randomized into eight groups of eight animals: five groups were treated with the different $G$. sempervirens dilutions, one group with buspirone and two groups with the vehicle (control). Two groups of control vehicle-treated animals were included both to obtain highly consistent reference values for calculating the drug effects and to permit comparison of two identical groups to determine the between-group stability of the experimental setting.

All the experiments were performed between 09:00 and 14:00 (LD) and between 09:00 and 15:00 (OF). The solutions were administered in the morning for nine consecutive days (including on the last two days when the animals were tested) by intraperitoneal (i.p.) injection $(0.3 \mathrm{ml} / \mathrm{mice})$. The treatments were administered row by row, and the behavioral tests started $30 \mathrm{~min}$ after drug injections. The animals were tested individually in four separate devices, allowing a complete set of up to 64 mice ( 8 animals $\times 8$ groups) to be tested during a $4-5 \mathrm{~h}$ experimental session.

\section{Behavioral tests}

The experiments were performed in the following order: open-field (OF) exploration test on day one (8th day of drug administration) and light-dark choice test (LD) on the following day (9th day of drug administration). Just before testing, the animals were allowed to acclimate to the room inside their cages for $3 \mathrm{~min}$ after being moved from their customary housing area. The operators stayed outside the testing room during recording of the experimental sessions.
Aside from the treatment injections and testing, the animals were not subjected to pain or other forms of emotional or physical stress.

Open-field test

The OF test (Prut and Belzung 2003; Simon et al. 1994; Walsh and Cummins 1976) was performed by placing an animal for $10 \mathrm{~min}$ in an environment consisting of a $50 \times$ $50 \mathrm{~cm}$ black-painted wood platform with $25-\mathrm{cm}$ high surrounding walls illuminated with white light $(100 \mathrm{~lx})$. To evaluate central exploratory propensity, the arena was divided virtually into two parts, with a square central zone having an area corresponding to $25 \%$ of the total area. The apparatus was cleaned thoroughly with water and soft disposable paper between trials, and with water and detergent between experiments.

\section{Light-dark test}

The LD test (Bourin and Hascoet 2003; Chen et al. 2004; Hascoet et al. 2001) apparatus used consisted of a small, secure dark compartment $(15 \times 30 \mathrm{~cm})$ and a large, aversive illuminated compartment $(30 \times 30 \mathrm{~cm})$. The two compartments were separated by a partition with an opening (4x $4 \mathrm{~cm}$ ) through which the animal could pass from one compartment to the other. The aversive compartment was illuminated with $200 \mathrm{~lx}$. The animals were placed in the center of the lit compartment facing the opening and left to explore the space for a 5-min testing period. The number of transitions between the light and dark compartments in the LD test was also evaluated on the screen by an operator who was unaware of the group assignment of the mice. The apparatus was cleaned thoroughly between trials.

\section{Video tracking}

All the sessions were recorded with a video-tracking camera (GZ-MG135, JVC, Japan) and stored on DVD. A software program ("Smart" VTS system from PanLab, Barcelona, E) was used to automatically trace the position and movements of the animals and calculate the time spent in different zones and the distance traveled. All behavioral recordings were carried out with the observer unaware of the treatment group assignment of the mice.

\section{Statistics}

All analyses were performed using the SPSS software, version 17 (SPSS Inc., Chicago, IL, USA: http://www.spss. com). All data are represented as mean \pm SEM values. The Shapiro-Wilk test indicated that the data obtained were parametric. The groups were compared by two-way 
analysis of variance, using the treatment group and the experiment as the factors. Post hoc $t$ tests were performed assuming equal variances with least significant difference (LSD) corrections to adjust for multiple comparisons.

The net effect of the drugs was calculated in standardized form as a percentage relative to the mean values of all the controls in each experiment (taken as zero effect) according to the formula:

[(Test value of each mouse/mean test value of 16 control mice $)-1]$

$\times 100$.

This allowed the effects observed in all the experiments to be pooled, compared and statistically evaluated.

\section{Results}

\section{Open-field test}

The mean values of each OF experiment and the mean values \pm S.E.M. of all experiments, with statistical evaluations, are reported in Tables 1, 2 and 3. Table 1 shows the total distance traveled in the whole of the open-field arena. This parameter does not reflect changes in emotional behavior, but is important for evaluating the total locomotor activity of the animals during the 10-min trial. $G$. sempervirens dilutions did not change these values as compared with the untreated control animals, except for the $5 \mathrm{C}$ dilution which produced an increase in this parameter that only narrowly missed statistical significance $(p=$ 0.052 ). Buspirone caused a small, but statistically significant $(p=0.002)$, decrease in the total distance traveled in the field, suggesting a possible sedative effect of this drug at the dosage used.

The two major behavioral variables evaluated in the OF test were the percentage time spent in the central zone of the field (Table 2) and the distance traveled in the central zone (Table 3). As shown in Table 1, there was significant variability between experiments $(p<0.001)$ but no interaction between experiments and groups, indicating that any observed drug effects were not influenced by interexperiment differences. In most of the experiments, some $G$. sempervirens dilutions appeared to increase the time spent in the central zone. The values of the group treated with $G$. sempervirens $7 \mathrm{C}$ were higher than the mean of the controls in all experiments, while those of the 9C group were higher in all cases but one (experiment no. 6). However, global ANOVA for the groups yielded a value of only $p=0.063$, precluding post hoc analysis to evaluate the statistical significance of individual dilutions. The experiments did not reveal any clear and reproducible dose-dependence relations. The standard drug buspirone

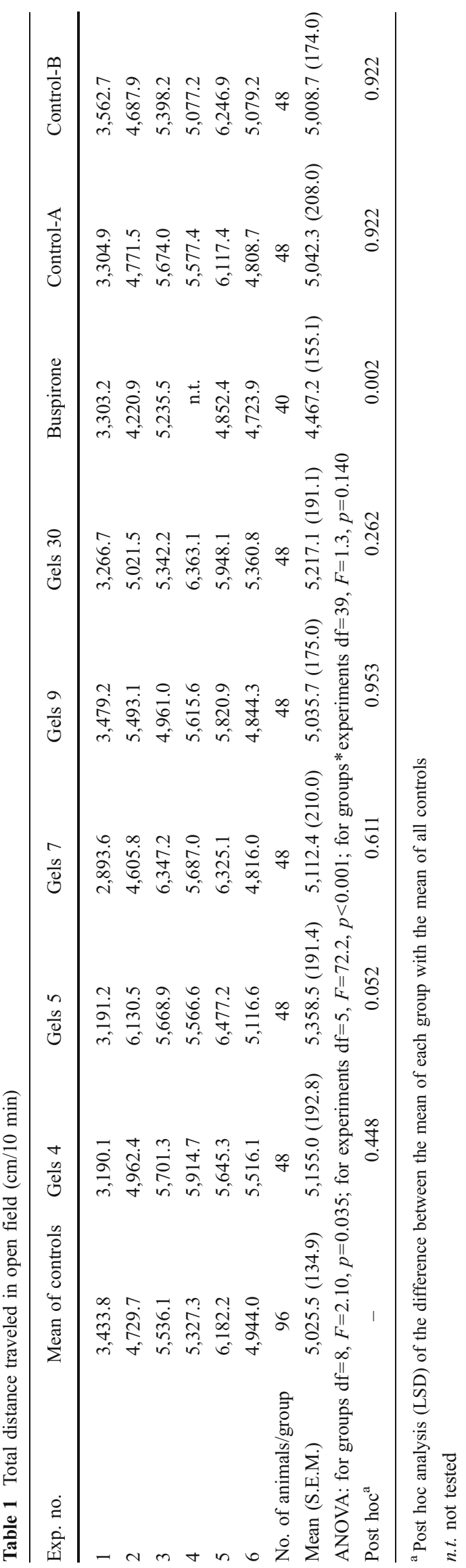


Table 2 Permanence time in the center area of open field ( $\%$ of total time)

\begin{tabular}{lccccccccc}
\hline Exp. no. & Mean of controls & Gels 4 & Gels 5 & Gels 7 & Gels 9 & Gels 30 & Buspirone & Control-A & Control-B \\
\hline 1 & 6.7 & 6.2 & 8.4 & 9.0 & 8.5 & 7.1 & 7.8 & 6.9 & 6.5 \\
2 & 13.0 & 11.1 & 13.4 & 19.4 & 15.9 & 15.8 & 12.6 & 14.2 & 11.9 \\
3 & 15.0 & 17.8 & 15.6 & 16.2 & 17.8 & 17.5 & 16.5 & 15.7 & 14.4 \\
4 & 15.2 & 18.5 & 19.0 & 16.8 & 17.9 & 15.8 & $n . t$. & 16.7 & 13.7 \\
5 & 17.5 & 13.8 & 16.3 & 18.3 & 19.1 & 18.2 & 14.7 & 18.1 & 16.8 \\
6 & 14.3 & 11.2 & 14.8 & 16.4 & 12.5 & 17.8 & 19.4 & 14.9 & 13.6 \\
No. of animals/group & 96 & 48 & 48 & 48 & 48 & 48 & 40 & 48 \\
Mean (S.E.M.) & $13.6(0.6)$ & $13.1(0.9)$ & $14.6(0.8)$ & $16.0(1.1)$ & $15.3(1.0)$ & $15.4(1.2)$ & $14.2(1.0)$ & $14.5(0.8)$ & $12.8(0.8)$ \\
ANOVA: for groups $\mathrm{df}=8, F=1.87, p=0.063$; for experiments df=5, $F=30.1, p<0.001 ;$ for groups * experiments df=39, $F=0.75, p=0.858$ \\
\hline
\end{tabular}

n.t. not tested

had little or no effect on the time spent in the central zone. Similar results were observed for the distance traveled in the center of the OF (Table 3): G. sempervirens 5C, 7C, 9C and $30 \mathrm{C}$ showed a slight tendency to increase the distance traveled in the central zone, while buspirone tended to decrease the same parameter; however the magnitude of these effects did not reach the threshold of statistical significance.

\section{Light-dark test}

The mean values of each LD experiment and the mean values \pm S.E.M. of all experiments, with statistical evaluations, are reported in Tables 4 and 5. Also in this test, there was a significant difference between experiments $(p=$ 0.002 ) but no interaction between groups and experiments. In the LD test, most $G$. sempervirens dilutions and the conventional anxiolytic reference drug proved to be significantly effective (global ANOVA for groups $p=$ 0.002 and $p=0.001$ for the data of Tables 4 and 5, respectively). The percentage time spent in the illuminated compartment (Table 4) was significantly increased by the 5C and 9C G. sempervirens dilutions, while 30C exhibited a borderline significance. The $9 \mathrm{C}$ dilution had a greater effect than the mean of the controls in all experiments and showed the highest statistical significance $(p<0.001)$. However, no clear dose-dependence relation was apparent in this series of experiments. The standard drug buspirone increased the time spent in the illuminated compartment, as expected, thus confirming the sensitivity of the test.

The results for the number of transitions between compartments (Table 5) showed a similar stimulatory effect of $G$. sempervirens dilutions. However, buspirone, compared to the control, had a lesser effect on the number of transitions than it had on the time spent in the lit compartment. Since the number of transitions are dependent on locomotor activity, this may be related to a small sedative effect, as also observed in the OF test.
The importance of the anxiolytic-like effects of $G$. sempervirens in this test is reinforced by the observation that the two separate groups treated with the control vehicle produced similar scores, and both were different from those of the verum-treated groups.

\section{Summary of percentage effects}

The results of all the experiments were pooled after standardizing the values for each mouse with respect to the mean value for the control mice of that experiment. The differences between each control vehicle-treated mouse, relative to the mean value of all the controls in the same experiment, were also computed. This made it possible to evaluate the variation between the two control groups and the stability of the system. A summary of the main results of this investigation is provided in Fig. 2. The mean percentage effect value for all the mice in the treated groups clearly shows a small increase due to $G$. sempervirens dilutions in the OF paradigm (panels $\mathrm{A}$ and $\mathrm{B}$ ). In the $\mathrm{OF}$, the G. sempervirens-treated animals $(5 \mathrm{C}, 7 \mathrm{C}, 9 \mathrm{C}$ and $30 \mathrm{C}$ ) exhibited $10-20 \%$ higher activity than the control. However, due to inter-individual variability of responses, these effects did not attain statistical significance in global ANOVA analysis. Buspirone had small, non-significant, effect on the amount of time spent in the center (panel A) and showed a tendency to inhibit the distance traveled in the center (panel B).

G. sempervirens treatment caused a markedly significant increase in the parameters of the LD paradigm (panels $\mathrm{C}$ and D). Here, the most active G. sempervirens solutions (5C, 9C and 30C) increased the parameters, considered to be a sign of reduced anxiety, by $20-40 \%$. With respect to time spent in the light compartment, this effect was comparable to that of buspirone, while in terms of the number of transitions, the effect of G. sempervirens $9 \mathrm{C}$ and $30 \mathrm{C}$ was much higher and more significant than that of buspirone. This was probably due to a sedative effect of 

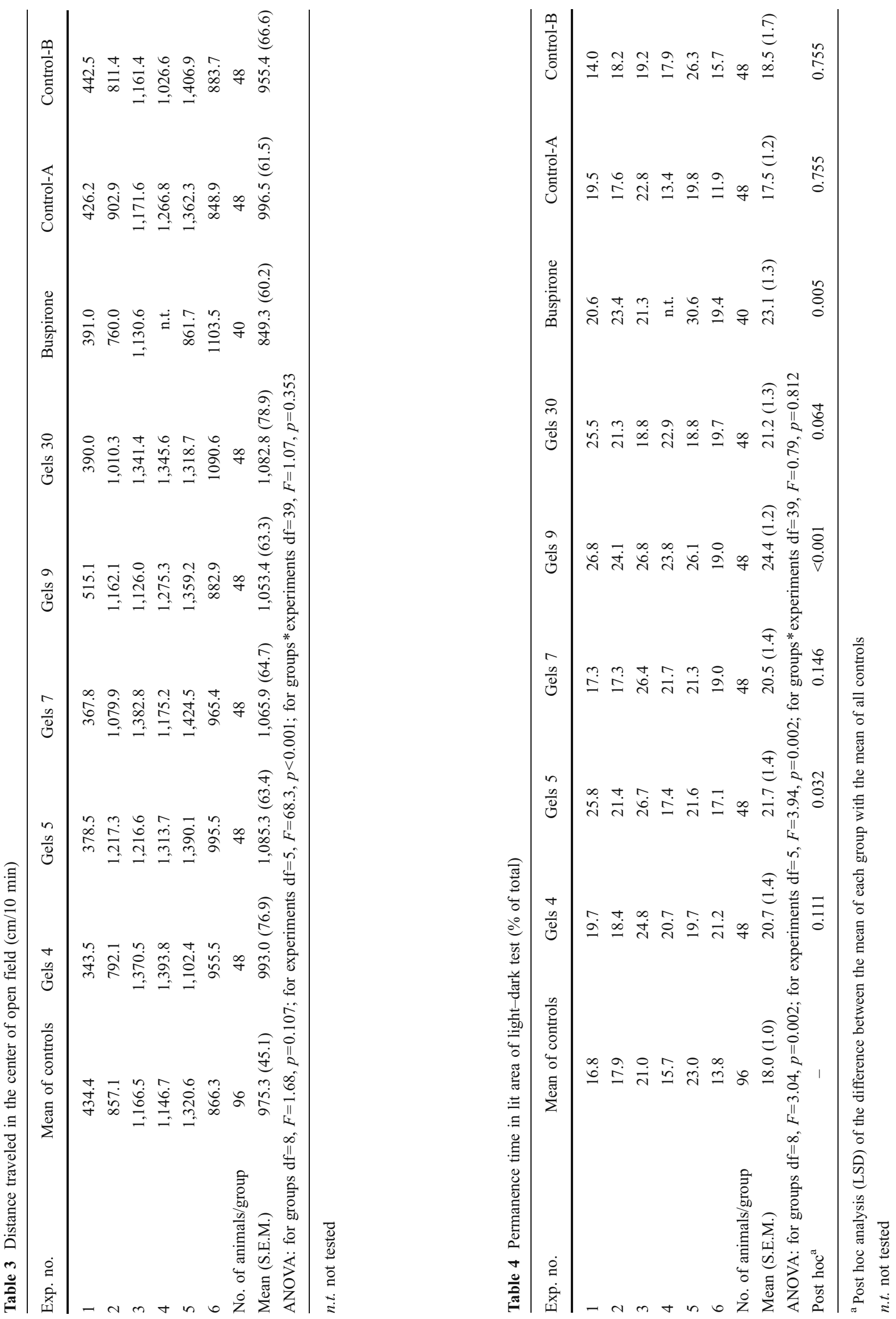
Table 5 Transitions between compartments of light-dark test ( $\mathrm{n} / 5 \mathrm{~min})$

\begin{tabular}{|c|c|c|c|c|c|c|c|c|c|}
\hline Exp. no. & Mean of controls & Gels 4 & Gels 5 & Gels 7 & Gels 9 & Gels 30 & Buspirone & Control-A & Control-B \\
\hline 1 & 5.6 & 5.6 & 5.1 & 5.1 & 6.8 & 9.2 & 5.9 & 6.5 & 4.7 \\
\hline 2 & 6.5 & 6.6 & 9.6 & 6.3 & 10.4 & 8.2 & 8.0 & 6.6 & 6.4 \\
\hline 3 & 7.2 & 9.5 & 8.6 & 9.6 & 9.5 & 6.5 & 6.9 & 6.7 & 7.6 \\
\hline 4 & 6.4 & 7.3 & 7.4 & 7.7 & 9.5 & 11.5 & n.t. & 6.7 & 6.1 \\
\hline 5 & 8.2 & 7.7 & 9.0 & 9.1 & 9.7 & 9.9 & 7.3 & 6.5 & 9.9 \\
\hline 6 & 4.5 & 8.5 & 7.4 & 6.4 & 7.3 & 7.1 & 6.6 & 4.9 & 4.1 \\
\hline No. of animals/group & 96 & 48 & 48 & 48 & 48 & 48 & 40 & 48 & 48 \\
\hline Mean (S.E.M.) & $6.4(0.4)$ & $7.5(0.6)$ & $7.9(0.6)$ & $7.4(0.5)$ & $8.9(0.6)$ & $8.7(0.6)$ & $6.9(0.4)$ & $6.3(0.5)$ & $6.5(0.6)$ \\
\hline \multicolumn{10}{|c|}{ ANOVA: for groups $\mathrm{df}=8, F=3.29, p=0.001$; for experiments $\mathrm{df}=5, F=5.08, p<0.001$; for groups $*$ experiments $\mathrm{df}=39, F=0.78, p=0.820$} \\
\hline Post hoc ${ }^{\mathrm{a}}$ & - & 0.096 & 0.034 & 0.152 & $<0.001$ & 0.001 & 0.472 & 0.920 & 0.920 \\
\hline
\end{tabular}

${ }^{\text {a }}$ Post hoc analysis (LSD) of the difference between the mean of each group with the mean of all controls

n.t. not tested

buspirone which reduced the movement speed of the mice, an effect that was not observed using diazepam $(1 \mathrm{mg} / \mathrm{kg}$ in acute treatment) in a separate experiment done under the same conditions (data not shown). The control groups A
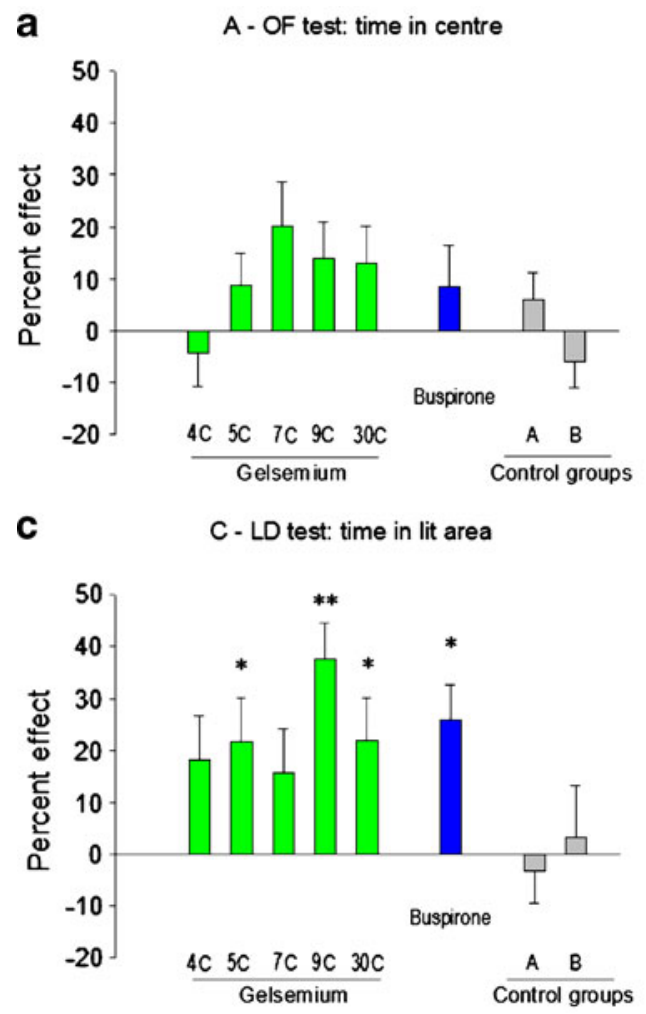

Fig. 2 Effects of G. sempervirens dilutions and of buspirone on OF (a and b) and LD (c and d) behavioral parameters, expressed as percentages \pm S.E.M. relative to the mean values for the vehicletreated, control animals. $N=48$ and 40 animals for $G$. sempervirenstreated and buspirone-treated groups, respectively. Global ANOVA values for these evaluations were: panel $A$ for experiments $\mathrm{df}=5, F=$ 0.97, $p=0.438$; for groups $\mathrm{df}=8, F=1.89, p=0.060$; panel $B$ for experiments $\mathrm{df}=5, F=2.72, p=0.020$; for groups $\mathrm{df}=8, F=1.39, p=$ 0.196 ; panel $C$ for experiments $\mathrm{df}=5, F=2.51, p=0.029$; for groups and B showed, in the various experimental models, a variability (positive and negative) relative to the mean that did not exceed $5 \%$, tending to support the conclusion that the drug effects are real and not attributable to chance.
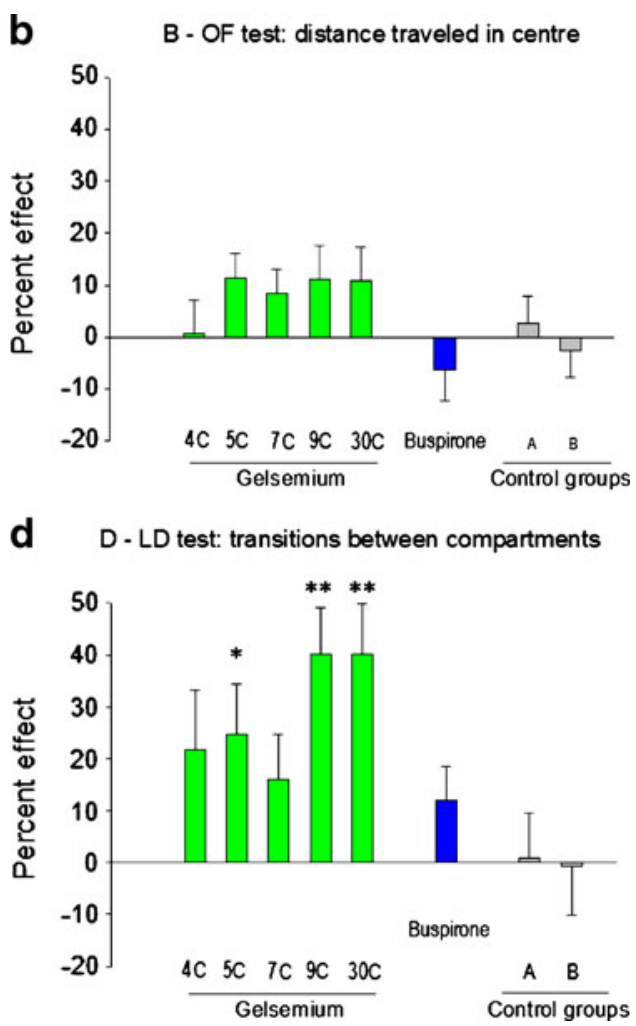

$\mathrm{df}=8, F=3.11, p=0.002$; panel $D$ for experiments $\mathrm{df}=5, F=2.97, p=$ 0.012 , for groups $\mathrm{df}=8, F=3.35, p=0.001$. All interactions between groups and experiments were not significant. The $p$ values $\left({ }^{*} p<0.05\right.$; $\left.*^{*} p<0.001\right)$ are from LSD-post hoc analysis by two-way ANOVA, comparing drug-treated groups or vehicle-treated groups (control groups A and B) with the mean of the corresponding control, vehicle-treated groups. LSD-post hoc analysis was not performed on data of panels A and B because global ANOVA was beneath the significance threshold 


\section{Discussion}

Benzodiazepines have monopolized the anxiety market for some 40 years, but their potential for tolerance and dependence has stimulated interest in alternative anxiolytics. Attention has focused on drugs such as monoamine oxidase inhibitors, tricyclic antidepressants, selective serotonin reuptake inhibitors and the 5-HT1A partial agonist, buspirone (Bandelow et al. 2002; Allgulander et al. 2003). The challenge for the future is not only to find efficacious treatments with an acceptable side-effect profile, but also to determine the optimal compounds for each of the different anxiety disorders. Recently, there has been increased attention on the ways to cost effectively meet the demand for treatment so as to contain health service expenditure (Morgan and Jorm 2009). Anxiety and depression are among the symptoms most frequently reported by patients seeking complementary and alternative medical treatments, homeopathy and natural remedies (Mathie and Robinson 2006; Thompson et al. 2008; Greeson et al. 2008; Guethlin et al. 2009).

G. sempervirens is one of the classical remedies used in complementary medicine for treating patients who exhibit neurological anxiety-like symptoms. In traditional Materia Medica (Boericke 1927), G. sempervirens is described as a cure for a variety of neurological and behavioral symptoms such as general prostration, dizziness, drowsiness, dullness, trembling, tired feeling, mental apathy, muscular weakness, prostration, lack of muscular coordination, general depression caused by heat of the sun, emotional excitement, ill effects provoked by fear or exciting news and so on. In summary, the action of the remedy is centerd on the nervous system, and effects on anxiety-like behavioral symptoms have been suggested (Barbancey 1987; Guermonprez 2006) but not proven. As in the case of many other alternative remedies, evidence of clinical and pre-clinical (laboratory and animal models) efficacy is scarce or completely lacking (Carpenter and Neal 2005; Pilkington et al. 2006a).

Our experiments provide firm evidence that various G. sempervirens dilutions have an anxiolytic-like effect on mice in the LD test, without any effects on the locomotor component assayed by OF test. The effects of some of the tested doses of G. sempervirens, namely $9 \mathrm{C}$ and $30 \mathrm{C}$, on the time spent in the lit area of the LD test were comparable to or even better than those of the standard anxiolytic buspirone.

In the OF paradigm, G. sempervirens produced a slight, but not significant increase in the amount of time spent in the center of the field, while buspirone did not have any significant effects. A possible explanation for this scarcity of results in the $\mathrm{OF}$ test could be that in the experimental conditions of this investigation, this test was insufficiently sensitive for detecting anxiety and drug-related anxiolytic effects. Others have reported that anxiolytic treatments do not in and of themselves increase exploration in the central zone of the $\mathrm{OF}$, but rather that they counteract stressinduced inhibition of exploratory behavior (Bourin et al. 2007). Since our experimental setting did not involve prior exposure to stress, it is possible that under such conditions the response of the mice to the drugs was slight. This interpretation appears consistent with that of Bousta et al. (2001) who report some anxiolytic-like effects of $G$. sempervirens in mice stressed by repeated electric shock, but no effects on normal mice.

A further problem with interpreting the $\mathrm{OF}$ data of this investigation arises from the significant reduction in the unspecific locomotor component produced by buspirone, whereas the $G$. sempervirens dilutions did not cause such an effect. Buspirone was administered over a period of 8 9 days in parallel with $G$. sempervirens on the grounds that it is a standard reference drug suited to chronic treatments since it does not develop the tolerance typical of benzodiazepines (Miller and Koff 1994; Khan and Haleem 2007). It is possible that, at the doses used and in these particular experimental conditions, buspirone might have induced a serotoninergic syndrome that interfered with locomotor activity and anxiolytic-like effects. Mild anxiolytic-like effects accompanied by a reduction in measures of general activity, produced by buspirone at doses of $2.5-5.0 \mathrm{mg} / \mathrm{kg}$, have been reported by others (Cole and Rodgers 1994). It remains to be established whether lower doses of buspirone might avoid causing this unwanted side effect whilst maintaining their anxiolytic-like activity. In any case, the doses used in this investigation fell within the mean range of those commonly employed for detecting anxiolytic-like effects in rodents (Costall et al. 1989; Young and Johnson 1991b; Merali et al. 2003; Harada et al. 2006; Young et al. 2006; Grundmann et al. 2007; Pogorelov et al. 2007; Yamauchi et al. 2008). That said, given the tendency of buspirone to produce general behavioral suppression, it might be advisable in future research to employ a different drug (e.g. water-soluble benzodiazepine) as a positive control in similar experimental settings.

A comparison of the data for the two test models shows that the anxiolytic-like effects of G. sempervirens and buspirone were higher and more significant in the LD than in the OF test. This difference may be due to a number of reasons. A first possibility is that the two tests explore distinct behavioral aspects that are affected in different ways by the remedies, as also borne out by their differing sensitivity to the conventional drug buspirone. The light/ dark box is widely used with rodents as a model for screening anxiolytic or anxiogenic drugs, based on the innate aversion of rodents to brightly lit areas and the spontaneous exploratory behavior of rodents in response to 
mild stressors - such as are novel environments and light (Crawley and Goodwin 1980). Belzung and Griebel suggest that the light-dark test and the elevated plus-maze are the most appropriate devices for assessing "state anxiety", whereas the free-exploratory paradigm can be used for "trait anxiety" (Griebel et al. 1993; Belzung and Griebel 2001). However, the open-field test is also used as a model of state anxiety (Bourin et al. 2007), and there are few true trait-anxiety animal models, with those in use relying on genetic paradigms or chronic exposure to fear-provoking stimuli.

An alternative explanation is that testing the animals on two successive days might have changed the baseline anxiety level, and, hence, their response to the treatments. It has been noted that the extent to which an anxiolytic compound can facilitate exploratory activity depends on the baseline level of anxiety in the control group (Hascoet et al. 2001). Since our experimental setting did not involve prior exposure to stress and the mice were naïve to testing when the OF test was performed on the first day of trials, it is possible that in those conditions the response of the mice to G. sempervirens was low because their level of basal anxiety, as assessed by the OF test, was lower. The anxiety level of the animals might have increased on the second day of trials, and this could have induced a higher response to the treatments in the LD test. Differences between the type and severity of external stressors, and between the experimental setups, might account for the high variability of results reported under different experimental conditions and by different laboratories (Bourin et al. 2007).

The problem of dosage is obviously central to pharmacology. From the pooled data of all the experiments, there emerges clear and consistent evidence indicating that lower dilutions (4C) were less effective (or entirely inactive on the OF parameters) than higher dilutions (9C and 30C). However, the pattern is much more complex since, in the LD test where the most significant data were observed, the 7C and 30C dilutions showed lower effects than $5 \mathrm{C}$ and $9 \mathrm{C}$, respectively. A number of observations - coming from several research fields (Belougne-Malfatti et al. 1998; Brown and Ennis 2001; Marotta et al. 2003; Belon et al. 2004; Eizayaga et al. 2005; Bellavite et al. 2006b; Witt et al. 2007; Ruiz-Vega and Estevez-Delgado 2008; Chirumbolo et al. 2009) - suggest that in high-dilution pharmacology, there is no linear or proportional relation between the molecular concentration of active substances and the therapeutic effect. Thus far there is no satisfactory or unifying theoretical explanation for these claims, though some hypotheses suggest a role of the nano-heterogeneous structures and dynamics of the solvent water (or water-ethanol) on a mesoscopic scale (Arani et al. 1995; Del Giudice and Preparata 1998; Smith 2004) and/or of epitaxy (Demangeat et al. 2004; Elia et al. 2004, 2007; Mastrangelo 2007; Rao et al. 2007; Chaplin 2007; Demangeat 2009).
A possible neurological target of $G$. sempervirens in high dilutions has recently been identified by studies showing that gelsemine, the main component of $G$. sempervirens, stimulates biosynthesis of allopregnanolone $(3 \alpha, 5 \alpha$-THP) in the central nervous system of rats through activation of receptors for glycine (Gly-R) (Venard et al. 2008). More recently, the same group has shown that the 5C and 9C dilutions of G. sempervirens and of pure gelsemine stimulate the synthesis of $3 \alpha, 5 \alpha$-THP in both the hippocampus and the spinal marrow in vitro (Venard et al. 2009). A particularly interesting observation is that the effects of $G$. sempervirens in vitro were blocked by strychnine, a well-known selective inhibitor of glycinergic receptors. Because allopreganolone endogenously synthesized in the central nervous system significantly modulates anxiety or nociceptive mechanisms through paracrine and autocrine modes (Le Melledo and Baker 2004; Birzniece et al. 2006; Papadopoulos et al. 2006; Patte-Mensah et al. 2006), substances capable of stimulating $3 \alpha, 5 \alpha$-THP formation in neural networks appear potentially interesting for the development of effective anxiolytic or analgesic therapies.

To summarize, the results of this work show that some dilutions within the investigated dose range of G. sempervirens exert an anxiolytic-like effect on mice in the light/ dark test and, to a lesser extent, in open-field test. The remedy was found to augment the exploratory tendency in novel environments, without any effects on the motor coordination or sedation of the animals. This is one of the first traditional remedies, already empirically used in human patients for symptoms correlated with anxiety, to have been proven effective in experimental animals and for which there are some hypotheses as to its molecular targets in the central nervous system.

Acknowledgements This work was supported by grants from Laboratoires Boiron s.r.l. (Milan, Italy) to Verona University and from the Ministry of Universities and Science and Technology Research. We thank Dr. Paola D'Incau for carrying out the coding of the test samples and Dr. Jennifer Pascali for performing gas chromatography and mass spectroscopy on drug samples.

Conflicts of interest The authors declare that they have no competing interests.

Open Access This article is distributed under the terms of the Creative Commons Attribution Noncommercial License which permits any noncommercial use, distribution, and reproduction in any medium, provided the original author(s) and source are credited.

\section{References}

Allgulander C, Bandelow B, Hollander E, Montgomery SA, Nutt DJ, Okasha A, Pollack MH, Stein DJ, Swinson RP (2003) WCA recommendations for the long-term treatment of generalized anxiety disorder. CNS Spectr 8:53-61 
Arani R, Bono I, Del Giudice E, Preparata G (1995) QED coherence and the thermodynamics of water. Int J Mod Phys B9:1813-1841

Bandelow B, Zohar J, Hollander E, Kasper S, Moller HJ (2002) World Federation of Societies of Biological Psychiatry (WFSBP) guidelines for the pharmacological treatment of anxiety, obsessivecompulsive and posttraumatic stress disorders. World J Biol Psychiatry 3:171-199

Barbancey J (1987) Pratique Homéopathique en psycho-pathologie, Tome II. Editions Similia, Paris

Bellavite P, Conforti A, Ortolani R (2006a) Immunology and homeopathy. 3. Experimental studies on animal models. Evid Based Complement Alternat Med 3:171-186

Bellavite P, Conforti A, Pontarollo F, Ortolani R (2006b) Immunology and homeopathy. 2. Cells of the immune system and inflammation. Evid Based Complement Alternat Med 3:13-24

Bellavite P, Magnani P, Marzotto M, Conforti A (2009a) Assays of homeopathic remedies in rodent behavioural and psychopathological models. Homeopathy 98:208-227

Bellavite P, Magnani P, Zanolin E, Conforti A (2009b) Homeopathic doses of Gelsemium sempervirens improve the behavior of mice in response to novel environments. Evid. Based. Complement Alternat. Med. doi:10.1093/ecam/nep139

Belon P, Cumps J, Ennis M, Mannaioni PF, Roberfroid M, SainteLaudy J, Wiegant FA (2004) Histamine dilutions modulate basophil activation. Inflamm Res 53:181-188

Belougne-Malfatti E, Aguejouf O, Doutremepuich F, Belon P, Doutremepuich C (1998) Combination of two doses of acetyl salicylic acid: experimental study of arterial thrombosis. Thromb Res 90:215-221

Belzung C, Griebel G (2001) Measuring normal and pathological anxietylike behaviour in mice: a review. Behav Brain Res 125:141-149

Bilkei-Gorzo A, Gyertyan I, Levay G (1998) mCPP-induced anxiety in the light-dark box in rats - a new method for screening anxiolytic activity. Psychopharmacology (Berl) 136:291-298

Binsard AM (1979) Etude psycho-pharmacologique d'Ignatia et rapprochement avec un autre polychreste. Ann Homéop Fr 21:369-378

Binsard AM, Guillemain J, Platel A, Savini EC, Tetau M (1980) Etude psycho-pharmacologique de dilutions homéopathiques de Gelsemium et d'Ignatia. Ann Homéop Fr 22:35-50

Birzniece V, Backstrom T, Johansson IM, Lindblad C, Lundgren P, Lofgren M, Olsson T, Ragagnin G, Taube M, Turkmen S, Wahlstrom G, Wang MD, Wihlback AC, Zhu D (2006) Neuroactive steroid effects on cognitive functions with a focus on the serotonin and GABA systems. Brain Res Rev 51:212-239

Boericke W (1927) Materia medica with repertory, 9th edn. Boericke \& Tafel Inc, Santa Rosa

Bourin M, Hascoet M (2003) The mouse light/dark box test. Eur J Pharmacol 463:55-65

Bourin M, Petit-Demouliere B, Dhonnchadha BN, Hascoet M (2007) Animal models of anxiety in mice. Fundam Clin Pharmacol $21: 567-574$

Bousta D, Soulimani R, Jarmouni I, Belon P, Falla J, Foment N, Younos C (2001) Neurotropic, immunological and gastric effects of low doses of Atropa belladonna L., Gelsemium sempervirens L. and Poumon histamine in stressed mice. J Ethnopharmacol 74:205-215

Brown V, Ennis M (2001) Flow-cytometric analysis of basophil activation: inhibition by histamine at conventional and homeopathic concentrations. Inflamm Res 50(2):S47-S48

Carpenter JS, Neal JG (2005) Other complementary and alternative medicine modalities: acupuncture, magnets, reflexology, and homeopathy. Am J Med 118(Suppl 12B):109-117

Chaplin MF (2007) The memory of water: an overview. Homeopathy 96:143-150

Chen SW, Min L, Li WJ, Kong WX, Li JF, Zhang YJ (2004) The effects of angelica essential oil in three murine tests of anxiety. Pharmacol Biochem Behav 79:377-382
Chirumbolo S, Brizzi M, Ortolani R, Vella A, Bellavite P (2009) Inhibition of CD203c membrane up-regulation in human basophils by high dilutions of histamine: a controlled replication study. Inflamm Res 58:755-764

Choleris E, Thomas AW, Kavaliers M, Prato FS (2001) A detailed ethological analysis of the mouse open field test: effects of diazepam, chlordiazepoxide and an extremely low frequency pulsed magnetic field. Neurosci Biobehav Rev 25:235-260

Clement Y, Joubert C, Kopp C, Lepicard EM, Venault P, Misslin R, Cadot M, Chapouthier G (2007) Anxiety in mice: a principal component analysis study. Neural Plast 2007:35457

Cloos JM, Ferreira V (2009) Current use of benzodiazepines in anxiety disorders. Curr Opin Psychiatry 22:90-95

Cole JC, Rodgers RJ (1994) Ethological evaluation of the effects of acute and chronic buspirone treatment in the murine elevated plus-maze test: comparison with haloperidol. Psychopharmacology (Berl) 114:288-296

Costall B, Jones BJ, Kelly ME, Naylor RJ, Tomkins DM (1989) Exploration of mice in a black and white test box: validation as a model of anxiety. Pharmacol Biochem Behav 32:777-785

Crawley J, Goodwin FK (1980) Preliminary report of a simple animal behavior model for the anxiolytic effects of benzodiazepines. Pharmacol Biochem Behav 13:167-170

de Araujo FY, Silva MI, Moura BA, de Oliveira GV, Leal LK, Vasconcelos SM, Viana GS, de Moraes MO, de Sousa FC, Macedo DS (2009) Central nervous system effects of the essential oil of the leaves of Alpinia zerumbet in mice. J Pharm Pharmacol 61:1521-1527

Del Giudice E, Preparata G (1998) Coherence electrodynamics in water. In: Schulte J, Endler C (eds) Fundamental research in ultrahigh dilution and homeopathy. Kluwer, Dordrecht, pp 89-100

Demangeat JL (2009) NMR water proton relaxation in unheated and heated ultrahigh aqueous dilutions of histamine: evidence for an air-dependent supramolecular organization of water. J Mol Liquids 144:32-39

Demangeat JL, Gries P, Poitevin B, Droesbeke JJ, Zahaf T, Maton F, Piérart C, Muller RN (2004) Low-field NMR water proton longitudinal relaxation in ultrahighly diluted aqueous solutions of silica-lactose prepared in glass material for pharmaceutical use. Appl Magn Reson 26:465-481

Demarque D, Jouanny J, Poitevin B, Saint-Jean Y (1995) Pharmacologie et matière médicale homéopathique, 2nd edn. Boiron, C.E. DH, Lyon, France

Eizayaga FX, Aguejouf O, Belon P, Doutremepuich C (2005) Platelet aggregation in portal hypertension and its modification by ultralow doses of aspirin. Pathophysiol Haemost Thromb 34:29-34

Elia V, Baiano S, Duro I, Napoli E, Niccoli M, Nonatelli L (2004) Permanent physico-chemical properties of extremely diluted aqueous solutions of homeopathic medicines. Homeopathy 93:144-150

Elia V, Napoli E, Germano R (2007) The 'Memory of Water': an almost deciphered enigma. Dissipative structures in extremely dilute aqueous solutions. Homeopathy 96:163-169

Fukushiro DF, Benetti LF, Josino FS, Oliveira GP, Fernandes MD, Saito LP, Uehara RA, Wuo-Silva R, Oliveira CS, Frussa-Filho R (2009) Environmental novelty and illumination modify ethanolinduced open-field behavioral effects in mice. Pharmacol.Biochem.Behav. doi:10.1016/j.pbb.2009.12.001

Greeson JM, Rosenzweig S, Halbert SC, Cantor IS, Keener MT, Brainard GC (2008) Integrative medicine research at an academic medical center: patient characteristics and health-related qualityof-life outcomes. J Altern Complement Med 14:763-767

Griebel G, Belzung C, Misslin R, Vogel E (1993) The free exploratory paradigm: an effective method for measuring neophobic behaviour in mice and testing potential neophobia reducing drugs. Behav Pharmacol 4:637-644 
Grundmann O, Nakajima JI, Seo S, Butterweck V (2007) Anti-anxiety effects of Apocynum venetum $\mathrm{L}$. in the elevated plus maze test. $\mathrm{J}$ Ethnopharmacol 110:406-411

Guermonprez M (2006) Homéopathie, Principles-Clinique-Techniques. CEDH, Paris

Guethlin C, Walach H, Naumann J, Bartsch HH, Rostock M (2009) Characteristics of cancer patients using homeopathy compared with those in conventional care: a cross-sectional study. Ann Oncol. doi:10.1093/annonc/mdp421

Guillemain J, Rousseau A, Dorfman P, Tetau M (1989) Recherche en psychopharmacologie. Cah Biother 103:53-66

Harada K, Aota M, Inoue T, Matsuda R, Mihara T, Yamaji T, Ishibashi K, Matsuoka N (2006) Anxiolytic activity of a novel potent serotonin 5-HT(2C) receptor antagonist FR260010: a comparison with diazepam and buspirone. Eur J Pharmacol 553:171-184

Hascoet M, Bourin M, Dhonnchadha BA (2001) The mouse lightdark paradigm: a review. Prog Neuropsychopharmacol Biol Psychiatry 25:141-166

Irwin RE, Adler LS (2006) Correlations among traits associated with herbivore resistance and pollination: implications for pollination and nectar robbing in a distylous plant. Am J Bot 93:64-72

Khan A, Haleem DJ (2007) Tolerance in the anxiolytic profile following repeated administration of diazepam but not buspirone is associated with a decrease in the responsiveness of postsynaptic 5-HT-1A receptors. Acta Biol Hung 58:345-357

Lader M (2008) Effectiveness of benzodiazepines: do they work or not? Expert Rev Neurother 8:1189-1191

Lai CK, Chan YW (2009) Confirmation of gelsemium poisoning by targeted analysis of toxic gelsemium alkaloids in urine. J Anal Toxicol 33:56-61

Lamprea MR, Cardenas FP, Setem J, Morato S (2008) Thigmotactic responses in an open-field. Braz J Med Biol Res 41:135-140

Le Melledo JM, Baker G (2004) Role of progesterone and other neuroactive steroids in anxiety disorders. Expert Rev Neurother 4:851-860

Mamtani R, Cimino A (2002) A primer of complementary and alternative medicine and its relevance in the treatment of mental health problems. Psychiatr Q 73:367-381

Marotta D, Marini A, Banaudha K, Maharaj SV, Jonas WB (2003) Nonlinear effects of glutamate and $\mathrm{KCl}$ on glutamate toxicity in cultured rat cerebellar neurons. Int J Neurosci 113:491-502

Mastrangelo D (2007) Hormesis, epitaxy, the structure of liquid water, and the science of homeopathy. Med Sci Monit 13:SR1-SR8

Mathie RT, Robinson TW (2006) Outcomes from homeopathic prescribing in medical practice: a prospective, research-targeted, pilot study. Homeopathy 95:199-205

Merali Z, Levac C, Anisman H (2003) Validation of a simple, ethologically relevant paradigm for assessing anxiety in mice. Biol Psychiatry 54:552-565

Mi XJ, Chen SW, Wang WJ, Wang R, Zhang YJ, Li WJ, Li YL (2005) Anxiolytic-like effect of paeonol in mice. Pharmacol Biochem Behav 81:683-687

Miller LG, Koff JM (1994) Interaction of central and peripheral benzodiazepine sites in benzodiazepine tolerance and discontinuation. Prog Neuropsychopharmacol Biol Psychiatry 18:847-857

Morgan AJ, Jorm AF (2009) Outcomes of self-help efforts in anxiety disorders. Expert Rev Pharmacoecon Outcomes Res 9:445-459

Papadopoulos V, Lecanu L, Brown RC, Han Z, Yao ZX (2006) Peripheral-type benzodiazepine receptor in neurosteroid biosynthesis, neuropathology and neurological disorders. Neuroscience 138:749-756

Patte-Mensah C, Kibaly C, Boudard D, Schaeffer V, Begle A, Saredi S, Meyer L, Mensah-Nyagan AG (2006) Neurogenic pain and steroid synthesis in the spinal cord. J Mol Neurosci 28:17-31

Peredery O, Persinger MA (2004) Herbal treatment following postseizure induction in rat by lithium pilocarpine: Scutellaria lateriflora (Skullcap), Gelsemium sempervirens (Gelsemium) and Datura stramonium (Jimson Weed) may prevent development of spontaneous seizures. Phytother Res 18:700-705

Pilkington K, Kirkwood G, Rampes H, Fisher P, Richardson J (2006a) Homeopathy for anxiety and anxiety disorders: a systematic review of the research. Homeopathy 95:151-162

Pilkington K, Rampes H, Richardson J (2006b) Complementary medicine for depression. Expert Rev Neurother 6:1741-1751

Pogorelov VM, Lanthorn TH, Savelieva KV (2007) Use of a platform in an automated open-field to enhance assessment of anxiety-like behaviors in mice. J Neurosci Methods 162:222-228

Prut L, Belzung C (2003) The open field as a paradigm to measure the effects of drugs on anxiety-like behaviors: a review. Eur J Pharmacol 463:3-33

Ramos A, Pereira E, Martins GC, Wehrmeister TD, Izidio GS (2008) Integrating the open field, elevated plus maze and light/dark box to assess different types of emotional behaviors in one single trial. Behav Brain Res 193:277-288

Rao ML, Roy R, Bell IR, Hoover R (2007) The defining role of structure (including epitaxy) in the plausibility of homeopathy. Homeopathy 96:175-182

Ruiz-Vega G, Estevez-Delgado G (2008) Non-linearity modeling of ultra-dilutions: the histamine disturbances case. In: Bonamin LV (ed) Signals and images. Contributions and contradictions about high dilution research. Dordrecht: Springer Science, pp 67-82

Sainte-Laud J, Belon P (2009) Inhibition of basophil activation by histamine: a sensitive and reproducible model for the study of the biological activity of high dilutions. Homeopathy 98:186-197

Schosser A, Kasper S (2009) The role of pharmacogenetics in the treatment of depression and anxiety disorders. Int Clin Psychopharmacol 24:277-288

Schun Y, Cordell GA (1987) Cytotoxic steroids of Gelsemium sempervirens. J Nat Prod 50:195-198

Shimada T, Matsumoto K, Osanai M, Matsuda H, Terasawa K, Watanabe H (1995) The modified light/dark transition test in mice: evaluation of classic and putative anxiolytic and anxiogenic drugs. Gen Pharmacol 26:205-210

Simon P, Dupuis R, Costentin J (1994) Thigmotaxis as an index of anxiety in mice. Influence of dopaminergic transmissions. Behav Brain Res 61:59-64

Smith CW (2004) Quanta and coherence effects in water and living systems. J Altern Complement Med 10:69-78

Sukul NC, Bala SK, Bhattacharyya B (1986) Prolonged cataleptogenic effects of potentized homoeopathic drugs. Psychopharmacology (Berl) 89:338-339

Thompson LJ, Frazier K, Stiver S, Styer E (2002) Multiple animal intoxications associated with Carolina jessamine (Gelsemium sempervirens) ingestions. Vet Hum Toxicol 44:272-273

Thompson EA, Mathie RT, Baitson ES, Barron SJ, Berkovitz SR, Brands M, Fisher P, Kirby TM, Leckridge RW, Mercer SW, Nielsen HJ, Ratsey DH, Reilly D, Roniger H, Whitmarsh TE (2008) Towards standard setting for patient-reported outcomes in the NHS homeopathic hospitals. Homeopathy 97:114-121

Valnet J (1992) Phytothérapie. Maloine, Paris

Vasconcelos SM, Lima SR, Soares PM, Assreuy AM, de Sousa FC, Lobato RF, Vasconcelos GS, Santi-Gadelha T, Bezerra EH, Cavada BS, Patrocinio MC (2009) Central action of Araucaria angustifolia seed lectin in mice. Epilepsy Behav 15:291-293

Venard C, Boujedaini N, Belon P, Mensah-Nyagan AG, Patte-Mensah C (2008) Regulation of neurosteroid allopregnanolone biosynthesis in the rat spinal cord by glycine and the alkaloidal analogs strychnine and gelsemine. Neuroscience 153:154-161

Venard C, Boujedaini N, Mensah-Nyagan AG, Patte-Mensah C (2009) Comparative analysis of gelsemine and Gelsemium sempervirens activity on neurosteroid allopregnanolone formation in the spinal 
cord and limbic system. Evid Based Complement Alternat Med. doi:10.1093/ecam/nep083

Walsh RN, Cummins RA (1976) The open-field test: a critical review. Psychol Bull 83(3):482-504

Witt CM, Bluth M, Albrecht H, Weisshuhn TE, Baumgartner S, Willich SN (2007) The in vitro evidence for an effect of high homeopathic potencies - a systematic review of the literature. Complement Ther Med 15:128-138

Yamauchi M, Dostal J, Kimura H, Strohl KP (2008) Effects of buspirone on posthypoxic ventilatory behavior in the C57BL/6J and A/J mouse strains. J Appl Physiol 105:518-526
Young R, Johnson DN (1991a) Comparison of routes of administration and time course effects of zacopride and buspirone in mice using an automated light/dark test. Pharmacol Biochem Behav 40:733-737

Young R, Johnson DN (1991b) A fully automated light/dark apparatus useful for comparing anxiolytic agents. Pharmacol Biochem Behav 40:739-743

Young R, Batkai S, Dukat M, Glennon RA (2006) TDIQ (5, 6, 7, 8tetrahydro-1, 3-dioxolo[4, 5-g]isoquinoline) exhibits anxiolyticlike activity in a marble-burying assay in mice. Pharmacol Biochem Behav 84:62-73 